\title{
Law Enforcement and Transition
}

\author{
By: Gérard Roland and Thierry Verdier
}

Working Paper Number 262

May 1999 


\title{
Law enforcement and transition. ${ }^{x}$ Very preliminary!
}

\author{
Gérard Rolandy Thierry Verdier ${ }^{\mathrm{z}}$
}

October 4, 1999

\section{Introduction}

Nearly ten years after the fall of the B erlin wall, we can observe three different distinct kinds of trajectories of economic transition from socialism to capitalism.

A ..rst characteristic trajectory is that of countries of Central Europe that started the transition process in 1990. The transition strategy was mostly of the big bang type with the will to introduce most reforms as fast as possible with early price liberalization and stabilization and plans for mass privatization of state-owned enterprises. After an important initial output fall, those countries have found, at varying degrees, the way to economic recovery and growth. These countries are now expecting accession to the European Union. The two most characteristic countries in this category are Poland and the Czech republic. ${ }^{1}$

\footnotetext{
${ }^{x}$ T his project bene..tted from an ACE grant P96-6095R. The research was partly done while Gérard Roland was a Fellow at the Center for A dvanced Studies in the B ehavioral Sciences and bene..tted from ..nancial support by National Science Foundation Grant \# SBR-9022192. We thank Patrick B olton and Y ingyi Qian for discussions.

YECARE, Université Libre de Bruxelles.

zDELTA-ENS,

${ }^{1}$ One important dixerence between the two countries is the fact that privatization in Poland ended up to be of a gradual nature. Nevertheless, plans for mass privatization were seriously prepared. Due to political constraints, those plans were delayed for many
} 
A second trajectory is that of Russia. Russia also followed a strategy of fast reform that was very close in most respects to the strategy followed in Central Europe." Nevertheless, Russia has suxered from "shock without therapy " and has witnessed a continuous economic decline since the beginning of transition, culminating in the big default crisis of A ugust 1998.

A third trajectory is that of China. China has followed a very dixerent strategy from Eastern European countries. Its gradual approach to reforms led to a sequencing of reforms over a longer time horizon and to a dualtrack type of liberalization leading to a coexistence of a largely unreformed state sector with competitive non state enterprises developing everywhere else under very deregulated conditions.

How can we explain these dixerences in transition trajectories? A paradox is that dixerences in reform strategies are much smaller between Poland and Russia on one hand, and China on the other hand, but that there is such a big dixerence between the trajectories followed by Poland and Russia. How to explain such a big dixerence?

In this paper, we try to explain these three typical trajectories by emphasizing the dimension of law enforcement in transition. The vision that markets evolve spontaneously with liberalization put forward by many transition experts neglects another spontaneous emergence, namely that of criminal activity predating on private producers. Such a phenomenon reminds us of the importance of law enforcement to protect private economic activity from predatory behavior. This dimension has played a critical role in the takeox of industrialization in economic history (North, 1990) and is likely to play an important role in determining economic success and failure in transition economies.

Focusing on the dimension of law enforcement, we see immediately that it is a big problem in Russia with the rise of the ma..a phenomenon. It is less of a problem in Poland and China. The lack of the rule of law has led to an increase in predatory activities which are likely to have adverse exects on productive activity. The question is then: why is there law enforcement in some countries and less (or hardly any) in other countries, a question that is also relevant beyond the realm of transition economies. Since the rule of law

years. The Czech republic which, like R ussia, did implement a mass privatization plan is not performing as well as Poland. Still, the Czech republic's performance are clearly better than those of Russia.

${ }^{2}$ P rivatization in Poland ended up to be very gradual compared to R ussia. Nevertheless, the Czech republic has, like Russia, had an experience of mass privatization 
is enforced by government, the question is then: why are some governments too weak to enforce the law and thers are not?

One sees immediately that there is an important coordination problem to be solved in law enforcement. This coordination problem has at least two dimensions. First of all, for given expenditures on repression, strong law abidance by all citizens ensures exective repression whereas weak law abidance decreases the expectation of getting caught and thus the disincentive to break the law. On the other hand, coordination is also necessary to provide the public good of repression technology. This coordination is usually solved via tax collection, but tax collection itself is likely to be endogenously weak in countries where law enforcement is weak. These coordination problems in law enforcement typically lead to predict multiplicity of equilibria. Such multiplicity mayserve as a point of departure to explain why countries with similar reform strategies may have such dixerent outcomes in law enforcement.

However, multiplicity of equilibria does not provide us with great predictive power since we do not have well accepted theories to explain why some equilibria are selected and not others. Can we explain why there is law enforcement in some countries and not in others? In order to answer that question, we would like to know whether there are institutional mechanisms for eliminating the "bad " equilibrium?

In the context of transition, we identify two such mechanisms.

A ..rst mechanism is what we call "dualism", following the scenario of Chinese transition. Dualism is the coexistence of an unreformed state sector where the government keeps direct control over economic resources with a liberalized non state sector following market rules. The dual-track approach to liberalization has been seen as a mechanism for achieving allocative ef..ciency (Byrd, 1987, 1989; Sicular, 1988), as a pareto-improving mechanism to satisfy political constraints while achieving ed ciency (Lau, Qian and Roland 1997a,b), and as an instrument to prevent an output fall following liberalization (Roland and Verdier, 1999). In this paper, we point to a new interpretation of the bene.ts of dualism in transition, namely its law enforcement bene.ts. Indeed, keeping direct state control over suc cient economic resources to deter predatory activity is a way to both credibly eliminate the ..scal externality and to discourage predatory behavior, thus eliminating the bad equilibrium with low tax collection and low law enforcement. This points to an important trade-ox between the potential ed ciency costs of maintaining state control over resources and the bene.ts in coordination. There is also 
in the model an additional trade-ox between the el ciency losses of state control and the gain in tax distortions. Indeed, under the dualist scenario, the government needs to rely less on private sector taxation to ..nance its law enforcement apparatus, thereby reducing taxation distortions. This additional trade-ox has already been emphasized by Gordon, Bai and Li (1999).

The second mechanism we put forward is accession to the European Union. An alternative to direct state control as a way of eliminating the "bad" equilibrium is exernal borrowing. However, we show that reimbursement constraints may dynamically jeopardize the "good " equilibrium. We show that accession to the European Union, even without external borrowing, provides a mechanism to eliminate the "bad" equilibrium, provided the "accessing" country is small enough relative to the European Union. The channel through which this works relates to the dynamics of coordination with the enforcement externality. Since agents can predict that there will be law enforcement in the future, this can make them strictly better ox if they choose today to be producers rather then predators. We show that this intertemporal incentive exect can be suф cient to achieve law enforcement today, even without external borrowing to ensure suc cient repression apparatus today. Interestingly, we show that accession without conditionality is better than with conditionality because the latter case creates a coordination problem of its own that annihilates partly the positive exects of expected accession.

It is the enforcement externality that creates a wedge between the intertemporal payo to become a producer or a predator. Indeed, in order to eliminate the "bad" equilibrium given the enforcement externality, the repression technology must discourage any number of agents from deviating. However, since in the good equilibrium, no agents deviate, the equilibrium expected punishment for an agent who would consider deviating is higher, yielding a strictly lower payow than to producers. This interesting dynamic coordination exect with the enforcement externality allows also, under the dualistic scenario, to strictly reduce the amount of resources that must stay under government control in order to obtain credible law enforcement. To our knowledge, such dynamic exects related to en enforcement externality had not yet been put forward in the literature.

W hile the ..rst mechanism allows to explain the Chinese success in law enforcement, the second mechanism may explain why Central European countries are faring much better than Russia in terms of law enforcement, and also in terms of the exects of law enforcement on growth and economic per- 
formance.

Contrary to a widespread view in the transition literature, we do not consider ma..as as agents of private law enforcement substituting for the de..ciency of the state (Grossman, 199x; J ohnson, Kaufmann and Shleifer, $1997, \ldots$ ). While it is logical that businessmen develop their own private protection militias when the state is de..cient, subcontracting such activities to ma..as presents such an obvious holdup problem that would make most people reluctant to recur to such subcontracting.

Section 2 introduces the basic model of agents'choices. Section 3 develops the basic coordination problem of law enforcement. Section 4 presents the dualism model of enforcement. Section 5 discusses a dynamic model of borrowing to achieve law enforcement. Section 6 studies the dynamic analysis of the accession exects. Section 7 concludes.

\section{The model}

We start with a one period model. Take a transition economy where the population size is normalized to 1 . Individuals are atomistic and choose to

$$
\max _{\circledast} \circledast U^{R}+(1 ; \quad \circledast) U^{P}
$$

given the choices of others and where $\AA$ is the probability of being a predator (robber) and $\left(1_{i}{ }^{\circledR}\right)$ is the probability of being a producer: We denote $U^{R}$ and $U^{P}$ the utility from being respectively a predator and a producer. We assume risk neutrality throughout the paper and we restrict ourselves to symmetric Nash equilibria where individuals choose $₫$ optimally given that $₫$ is chosen by others.

In their economic activity, agents are assumed to meet another agent within the period according to a random matching process. Therefore, ${ }^{\circledR}$ is the probability of meeting a predator and $(1 ; B)$ is the probability of meeting a producer. When a producer meets a predator, he is robbed with probability 1 of his income: Otherwise, his income remains unaxected. We assume that when a predator meets another predator, their income remains likewise unaxected because they have nothing to rob from each other.

Income generated by private production is $\mathrm{AK}_{\mathrm{p}}$ with a marginal productivity $A>1$ and where $K_{p}$ denotes private capital. The total capital stock in the economy is equal to $\mathrm{K}$. Capital is assumed to be used inec ciently when 
managed by the state and yields a marginal productivity of 1 . In most of the analysis, we will assume $\mathrm{K}=\mathrm{K}_{\mathrm{p}}$ but we will see that retaining $\mathrm{K}_{\mathrm{i}} \mathrm{K}_{\mathrm{p}}$ under state control may have other exects than those directly related to economic ec ciency.

We assume a predator is caught with probability $q$ in which case he gets $0 .{ }^{3}$ When a producer is robbed, his income is also 0 but when he is not robbed, his income is taxed by the government at rate $i$ in order to ..nance law enforcement.Taking into account these payous and the random matching, expected payous from being a predator and a producer are respectively given by

$$
\begin{aligned}
& U^{R}=\left(\begin{array}{ll}
1 ; & \circledR
\end{array}\right) A K_{p}\left(\begin{array}{ll}
1 ; & q
\end{array}\right) \\
& U^{P}=\left(\begin{array}{ll}
1 ; & \circledR
\end{array}\right) A K_{p}(1 ; \quad i)
\end{aligned}
$$

As can be seen, both $U^{P}$ and $U^{R}$ increase with $K_{p}$ and decrease with ${ }^{\circledR}$. The latter exect is related to the matching assumption. P rivate production is discouraged when there is a lot of predatory activity but so is the latter because there are less producers to rob from their income. The main dixerence between both payous is the relative dixerence between $q$ and $i$.

Repression technology axects $q$ the probability a predator faces of being caught. We make several assumptions on q. First, we assume there is a ..xed cost $\mathrm{S}$ that must be bourne before repression technology can be made exective. This speci..cation seems realistic. Otherwise, in..nitesimal amounts of government expenditures on repression would still have some positive effect. We also assume that $q$ decreases with ${ }^{\circledR}$. This is again a reasonable assumption to make. The more predators there are the less easy it is to catch any single one of them (like in M oene, 1990). Finally, we assume that $q$ is a concave function of public expenditures above the ..xed cost threshold. Formally, we assume the following functional form

$$
\mathrm{q}\left(\operatorname{maxf} 0 ; \text { i S i }{ }^{\circ} \mathrm{B}+\mathrm{Gg}\right) \text { with }^{\circ}>0 ; \mathrm{q}(0)=0 ; \frac{@ q}{@ G}>0 ; \frac{\varrho^{2} q}{\varrho^{2} G}<0
$$

Given the above assumptions, a ..rst thing to see is that for a given $G$, $U^{P}>U^{R}$ and $B=0(） q>i$. In exect, in order to decide to be honest

\footnotetext{
${ }^{3}$ T his assumption can be interpreted in two ways: either the police catches the stolen goods of the predator or the punishment inficted on him is high enough so as to ouset his illegal gains.
} 
producers, individuals must face a higher expected disutility from being a predator relative to the disutility from taxation when being honest. The assumption of risk neutrality keeps things simple but the economic exects are realistic.

We assume that the repression technology is such that $\mathrm{q}\left(\mathrm{i} \mathrm{Si}^{\circ}+\mathrm{K} i \mathrm{i}\right)>$ $i 8 i 2[0 ; 1):$ This means that the capital stock inherited from socialism, if used entirely for repression purposes, was suф cient to sustain as unique the equilibrium with ${ }^{\circledR}=0$, a reasonable assumption.

\section{The coordination problem in law enforce- ment}

We .rst look at the case of an economy where all the capital stock is privatized: $K_{p}=K$. The government then relies on the taxation of private income to ..nance repression technology. We thus have

$$
G=i(1 ; @) A K
$$

One is now facing a coordination problem. A gents will choose to be producers rather than predators if the probability of being caught as a predator is higher than the tax rate faced by honest producers. If all decide to be honest, then even a very low tax rate may suф ce to ..nance suф cient repression technology to deter predators. This is the "good" enforcement equilibrium. On the other hand, if many agents decide to become predators, they will each face a lower probability of being caught, increasing the incentive to become a predator. At the same time, in order to deter predators producers will face a higher tax rate, the smaller the number of honest producers, thereby encouraging them to be predators. We then have the "bad" equilibrium with no law enforcement. There will thus be multiplicity of equilibria because of this coordination problem.

De.ne $i$ such that $i=q($ i $S+i A K)$ : We can formulate the following proposition:

Proposition 1 For $i<i$ the only equilibrium involves $₫=1$. For $i>i$, there are three possible classes of equilibria with $\mathbb{B}=0$; $\mathbb{B}=1$ and $\mathbb{B}=\mathbb{\circledR}^{a} 2$ $(0 ; 1)$ : 
Proof of proposition 1: As seen above, $\circledast=0$ whenever $i<q$ and $\circledR=1$ whenever $i, q$ and $\mathbb{B}=\mathbb{B}^{a} 2(0 ; 1)$ whenever $i=q$. Given that $q$ is concave in $\mathrm{G}$ and that $\mathrm{q}(\mathrm{K} ; \mathrm{S})>i$; it follows that $\mathrm{q}(\operatorname{maxf} 0 ;$ i $\mathrm{S}+i \mathrm{AK} \mathrm{g})<$ $i 8 i<i$ and $q(i S+i A K)>i 8 i>i$. Below $i$, the only equilibrium can thus be $\circledast=1$. A bove $\dot{L}$, there are then Nash equilibria sustainable with $\AA=0$. If $®=1, G=q=0<i 8 i 2(0 ; 1]$ and $q=0$ for $i=0$. Equilibria with $\mathbb{B}=1$ are thus also sustainable. Since $q$ declines continuously in ${ }^{\circledR}$ and is concave in $i$; there exists a single value $\mathbb{B}^{\infty} 2(0 ; 1)$ for which $i$ $=q\left(i S ; \mathbb{B}^{a 0}+i\left(1 ; \mathbb{B}^{a}\right) A K\right)$. $¥$

A few remarks are in order. First, note that apart from the interior (unstable) equilibrium, $i$ can be indeterminate. It can be chosen arbitrarily in the equilibrium with ${ }^{\circledR}=0$ as long as it is larger than $i$ and it is irrelevant in the case with $\Theta=1$. In the former case, with $\Theta=0$, all is needed is to prevent any producer from deviating. The latter case ${ }^{\circledR}=1$ is somewhat reminiscent of the Russian situation where tax rates are considered to be high but are irrelevant because tax collection is low (see Berkowitz and Li, 1997). It seems reasonable that the tax rate is not determinate. Indeed, countries where one observes law enforcement are not necessarily countries with a big size of government. However, from the point of view of welfare, in the framework of the model, it is best to set $i$ as small as possible.

The multiplicity of equilibria is related to two externalities: the ..scal externality and the enforcement externality (Moene, 1990). The ..scal externality is due to the fact that people's choice of becoming a predator or a producer axects the tax base which in turn axects individual choices, and so on. It should be noted that these externalities are however not suф cient conditions to generate multiplicity. The ${ }^{\circledR}=1$ equilibrium can be eliminated if one assumes for example Inada conditions in private output and another assumption than random matching so that one has a strict incentive to deviate from ${ }^{\circledR}=1$ : (see for example Savvateev, 1998). In the current framework, the marginal product remains bounded at $A$ and nobody has an incentive to become a producer if surrounded by predators.

The multiplicity of equilibria should nevertheless be seen as relevant to understanding transition. Indeed, the massive societal change creates a huge coordination problem and coordination in law enforcement is one of the important coordination problems. Russia can be seen as an example of the bad equilibrium where there is little law enforcement and where predatory activities have an adverse exect on productive activity. Poland, and Central European countries candidates for accession to the European Union are 
examples of the good equilibrium.

Multiple equilibria are also present in the model of J ohnson, Kaufmann and Shleifer (1997) where the government and uno cial protection agencies compete to provide protection to ..rms. B ecause of ..scal externalities, there can be an equilibrium where producers pay their taxes and are protected by government and an equilibrium where it is to weak to outcompete private provision of protection.

Several questions are however raised:

-Can we know something about the selection of equilibria? ria?

- A re there transition strategies that eliminate the multiplicity of equilib-

In the rest of the paper, we focus on the latter question.

\section{Dualism as instrument for credible law en- forcement.}

An important reason for the ..scal externality is that massive transfer of ownership into private hands gives the government access to an eq cient repression technology only if it is able to collect suc cient tax revenues. This massive transfer may be the deliberate exect of policies of mass privatization to "get the state out of the economy" or of simple state collapse and private rent-grabbing. The outcome is the same. The bad equilibrium can therefore not be excluded since the government cannot levy taxes when private agents choose to be predators.

\subsection{Solving the coordination problem via government control.}

One possible way of eliminating the bad equilibrium is if the state keeps direct control over enough resources so as to keep a suф ciently exective repression apparatus. Even though such a policy is costly in terms of economic el ciency, it may be an important instrument for overcoming the coordination problem. The following proposition shows speci..cally how this works. 
Proposition 2 If $\mathrm{K} ; \mathrm{K}_{\mathrm{p}}>\mathrm{S}+{ }^{\circ}$ is left under state control and used to ..nance $G$, then there are only equilibria with $B=0$ provided $i$ is low enough. Welfare is maximized at $i=0$. Compared to the "good" equilibrium $(\Theta=0)$ under multiplicity, this equilibrium involves et ciency losses but economies in tax distortions.

Proof of proposition 2: Since $8 \mathrm{~K}_{\mathrm{p}}<\mathrm{K} i\left(\mathrm{~S}+{ }^{\circ}\right), \mathrm{q}$ i $\left.\mathrm{S}_{\mathrm{i}}{ }^{\circ}+\mathrm{K}_{\mathrm{i}} \mathrm{K}_{\mathrm{p}}\right)>$ 0 , it is always possible to set $i<q$, in which case either $®=1$ or any $\mathbb{B}>0$ cannot be an equilibrium since $U^{R}<U^{P}$. $U^{P}$ is maximized at $i=0$. Thus, as long as $K_{i} K_{p}=S+{ }^{\circ}+">0$ for any " $>0$, the good equilibrium can be sustained and the bad equilibrium eliminated.

In terms of welfare, implementing $\mathrm{q}\left(\mathrm{i}_{\mathrm{i}}{ }^{\circ}+\mathrm{K}_{\mathrm{i}} \mathrm{K}_{\mathrm{p}}\right)$ involves a trade-ow between eфc ciency losses and economies in tax distortions. Welfare is equal to $\mathrm{A}\left(\mathrm{K} \mathrm{i} \mathrm{Si}^{\circ}{ }_{\mathrm{i}}\right.$ ") compared to $(1 \mathrm{i} i) \mathrm{AK}$ under the good equilibrium with $\circledR=0$ under full privatization where $i=q\left(i S_{i} "+i A K\right)$ is, according to proposition 1, the minimum tax rate compatible with the good equilibrium and full privatization. Thus $i=\frac{q^{i}(i)+S+"}{A K}: \frac{q^{i}(i)}{A K}$ is a measure of the tax distortion. With no tax distortion under full privatization, the welfare loss is only of $S$ which is unambiguously smaller than $\mathrm{A}\left(\mathrm{S}+{ }^{\circ}+{ }^{\circ}\right)$ the welfare loss under partial privatization. $(A ; 1)(S+")$ is then the el ciency cost of the public sector while $A^{\circ}$ is the cost paid to eliminate the coordination problem due to the enforcement externality. Due to the tax distortion, $(1$ i $i) A K<$ $\left(1 \mathrm{i} \frac{\mathrm{S}+")}{\mathrm{AK}}\right) \mathrm{AK}$ the welfare level without tax distortion. If the tax distortion is small enough welfare is higher under full privatization, otherwise it may be smaller $¥$.

Note that using state control over resources is by assumption ined cient since the marginal product is smaller than 1 . The higher $\mathrm{A}$, the higher the cost of not privatizing and the higher the welfare dixerence between the good equilibrium under multiplicity and the unique equilibrium under incomplete privatization. However, there is a bene.t to state control, namely the elimination of the bad equilibrium. This exect of state control over resources as opposed to state taxation has not been put forward in the literature so far. There is also a second bene..t, namely the economy in tax distortion as in Gordon, Bai and Li (1998).

In equilibrium, $q$ is strictly greater than $i$ and $U^{P}$ is strictly greater than $U^{R}$. This wedge is necessary to prevent deviations from the enforcement 
equilibrium. However, this wedge will play an important role later when we extend the model to a dynamic model.

W ith the existence of a public sector, welfare is maximized at $i=0$ not because private taxation would be less ec cient as a means of ...nancing repression technology. It is more ec cient in the model. The reason $i=0$ is that this is the cheapest way, in terms of welfare, of deterring individuals to become predators rather than producers. If $i>0$, then it is necessary to increase q purely for incentive purposes which requires in turn that $i$ be set high enough.

Proposition 2 has a clear $\ddagger$ avor of the Chinese transition experience in at least two important ingredients: a) the state keeps direct control over resources; ${ }^{4}$ b) taxation of the non-state sector is kept at a minimum level. This dualistic feature is quite typical of Chinese transition. In China, taxation is very low. Tax revenues form only about 13\% of GDP, less than Russia! However, government-controlled industrial output is roughly $15 \%$ of GDP and government-controlled services form yet at least 10 additional percentage points of GDP. Thus, the Chinese government is less dependent on tax collection to ..nance government activities due to this dualism, in contrast to other transition economies where government has lost most of its control over resources.

The literature has so far emphasized the ec ciency and political economy aspects of dual-track liberalization (Sicular, 1988; Byrd, 1987, 1989; Lau et al. 1997a,b) and its ability to prevent output fall (Roland and Verdier, 1999). Here, we emphasize the law enforcement aspects of dualism. Interestingly, a key assumption necessary for dual-track liberalization to work is the state's enforcement capacity. Here, we have shown that dualism is a mechanism to obtain law enforcement. By keeping the tax rate as low as possible, one provides private agents with incentives to unambiguously become producers rather than predators. This comes at a cost, namely the waste of productive assets.

Nothing in the model guarantees that state resources will be used for repression technology. State resources may very well be diverted and control over state resources may be used for abuse of power. Since these questions are outside the model, we do not want to dwell too much on them. The model only shows some conditions necessary to obtain coordination in law

\footnotetext{
${ }^{4} \mathrm{~T}$ his direct control has obviously huge disadvantages not modeled here, Tien Anmen repression being one example.
} 
enforcement. Institutional guarantees for adequate use of resources would imply for example separation of powers with suc cient repressive power to the judiciary arm of government in order to refrain the executive from deviating from policy announcements, together with mechanisms for adequate selection of policies like electoral accountability.

\subsection{Dynamics of law enforcement.}

The above model was static. Even though we have shown how state control can be an adequate instrument for coordinating on the good equilibrium of law enforcement, there is no dynamics. If the above model is repeated twice or more, the result should be the same because there is no state variable.

In order to obtain dynamics, we thus introduce a two period model that will be useful for examining further instruments of guaranteeing law enforcement.

The most simple, and at the same time reasonable, modi..cation of the above model, is to assume that expenditures in repression technology can partly be seen as an investment. Many aspects of repression technology can be seen as investments that must be bourne initially but carry bene..ts into the future. Immediate examples that come to mind are the training of specialized police forces or the establishment of information networks on criminal activity. A nother example would be the establishment of reputation for eq ciency and incorruptibility which are initially very costly to achieve but are exective means of deterring criminal activity . In order to take into account this investment aspect of repression technology, we thus model expenditures in the following way:

$$
G_{t}=\left(\begin{array}{lll}
K & K_{p t}
\end{array}\right)+i t A K_{p t}\left(1 ; R_{t}\right)+\left(1 ; \quad \exists G_{t_{i}}\right.
$$

with $K_{p t}$ and $i_{t}$ as decision variables in period $t$ and $R_{t}$ the number of predators in period $t$.

The new element is the last term on the right hand side showing that past expenditures have persistence. The higher the \pm the lower the persistence.

We also assume that a choice to be a predator in period 1 cannot be reversed in period 2 while a choice to be a producer al ways can, a reasonable assumption it seems. This assumption will play an important role in the rest 
of the analysis. There will thus always be at least $R_{1}={ }_{1}$ predators in period 2. Call $\mathbb{B}_{2}$ the choice variable of an individual who was producer in period 2. The number of predators in period 2 is thus $R_{2}=\otimes_{1}+\left(1 ;{ }_{1}\right) \Theta_{2}<1$ : We also assume that undoing privatization is prohibitively costly so that it is, in exect, irreversible. This implies that $K_{p t}, K_{p t i} 1$.

We then get the following proposition.

Proposition 3 There is a unique enforcement equilibrium with $\mathbb{}_{1}=\mathbb{B}_{2}=0$ with gradual privatization $\mathrm{K}_{\mathrm{p} 2}=\mathrm{K}_{\mathrm{p} 1}=\mathrm{K}_{\mathrm{p}}^{\mathrm{\alpha}}$. M oreover $\mathrm{K}_{\mathrm{p}}^{\mathrm{a}}>\mathrm{K}_{\mathrm{i}}\left(\mathrm{S}+{ }^{\circ}+{ }^{\prime \prime}\right)$ the static privatization level, independently of \pm

Proof of proposition 3: In period 2, an individual who was producer in period 1 faces the choice of remaining a producer or becoming a predator. His choice is exactly the same as in the one period model. We will thus have $\mathbb{B}_{2}=0$ if $q_{2}>i_{2}$. Moreover, following proposition 2 , any $\mathbb{B}_{2}>0$ can be prevented if $i_{2}=0$ and $K_{p 2}$ is chosen such that

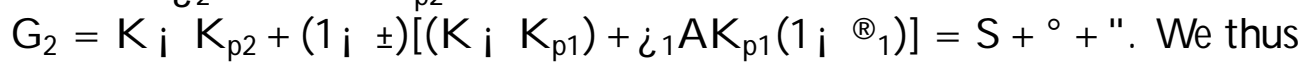
have $K_{p 2}=K\left(2 ; \pm i\left(1 ; \exists K_{p 1}+\left(1 ; 1_{i 1} A K_{p 1}\left(1 ;{ }_{1}\right) ;\left(S+{ }^{\circ}+"\right)\right.\right.\right.$ : Note already that $\mathrm{K}_{\mathrm{p} 2}>\mathrm{K} i\left(\mathrm{~S}+{ }^{\circ}+{ }^{\prime \prime}\right)$, the static model's level of privatization as soon as $\pm<1$.

Given the period 2 unique equilibrium with $\mathbb{B}_{2}=0$, and assuming that all repression technology is ..nanced by keeping resources under state control, thus with $i_{1}=0$;an individual prefers in period 1 to become a producer rather than a predator if

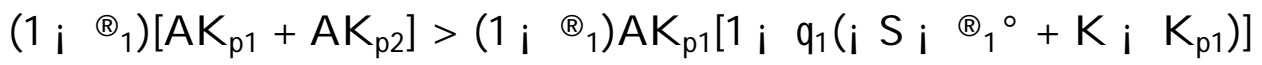

$$
\begin{aligned}
& +\left(1 ; \mathbb{R}_{1}\right) A K_{p 2}\left[1 ; \quad q_{2}\left(K ; K_{p 2}+\left(1 ; \quad \exists\left(K ; K_{p 1}\right) ;\left(S+\otimes_{1}{ }^{0}+"\right)\right)\right] 8 \Theta_{1}:\right.
\end{aligned}
$$

which gives simply the condition:

$$
\left(1 ; \mathbb{B}_{1}\right)\left[A K_{p 1} q_{1}+A K_{p 2} q_{2}\right]>08 \otimes_{1}<1
$$

with $q_{1}=q_{1}\left(i S ; \mathbb{B}_{1}{ }^{0}+K ; K_{p 1}\right)$ and $q_{2}$ being the equilibrium $q_{2}=$ $q_{2}\left(K ; K_{p 2}+\left(1 ; \exists\left(K ; K_{p 1}\right) ;\left(S+{ }^{\circ}+"\right)\right)\right.$ :Given that $\mathbb{B}_{2}=0, q_{2}\left(K_{i} K_{p 2}+\right.$ $\left(1 ; \exists\left(K_{i} K_{p 1}\right) ;\left(S+{ }^{\circ}+"\right)\right)$ is thus strictly $>0$ and 5 is always satis..ed 
for $\mathbb{B}_{1}<1$. Therefore any $\mathbb{R}_{1}>0$ equilibrium is eliminated and by continuity the $\AA_{1}=1 i^{\prime}$ ' equilibrium (for' arbitrarily small) is also eliminated. So the $\Theta_{1}=1$ equilibrium can be considered as eliminated at the limit. Note also that as soon as $q_{2}>0$, for any $\mathbb{B}_{1}<1$; the law enforcement equilibrium can be sustained with $q_{1}=0$ (with $i_{1}=0$ ) so that $K_{p 1}$ can not only be larger than $\mathrm{K} ;\left(\mathrm{S}+{ }^{\circ}+"\right)$, the equilibrium privatization level in the static model, but can even be equal to $\mathrm{K}$. Since we assume irreversibility of privatization, and since $\mathrm{K}_{\mathrm{p} 2}<\mathrm{K}$ is necessary for the enforcement equilibrium, we therefore have $K_{p 1}=K_{p 2}=K_{p}^{a}$ which following above's de. nition of $K_{p 2}$, evaluated at $\AA_{1}=1$ is then $K_{p}^{x}=K ; \frac{S+^{\circ}+": *}{2 i \pm}$

The ..rst part of proposition 3 is straightforward and just states that the enforcement equilibrium can be sustained as unique equilibrium. The second part stating that in the dynamic two period model, a higher level of privatization, i.e. a lower level of expenditures, can be sustained from the beginning of transition is less straightforward and relates both to the enforcement externality and to the assumption that the choice to become a predator is irreversible. The second period repression technology therefore serves strategically as a deterrent in the ..rst period, therefore reducing the need for deterrence in period 1. There is thus an intertemporal credible deterrent exect. The assumption of irreversible choice of predation acts in a way as a "trigger strategy " that allows to reduce expenditures on deterrence today. This intertemporal deterrent exect is so strong that if privatization were not irreversible, the enforcement equilibrium could be sustained with $\mathrm{K}_{\mathrm{p}}=\mathrm{K}$ in period 1.

\section{B orrowing as a substitute for dualism.}

If $A$ is very high, then the above strategy becomes very costly as a way to obtain law enforcement. It may then be better to borrow to pay the cost of credible enforcement and to relinquish state control over assets immediately at the beginning of transition. Such a strategy of borrowing will presumably be easier in the case of smaller countries like the $C$ entral European countries. We thus assume $\mathrm{K}_{\mathrm{pt}}=\mathrm{K}$ 8t. However, loans must be paid back. In period 1 , an amount $B$ is borrowed and is reimbursed in period 2 at interest rate $1 / 2$ It is assumed that a sovereign loan is reimbursed as long as tax revenues are suф cient for that purpose. There is thus no strategic default. We also 
assume as above that a choice to become a predator cannot be reversed:

What are under this scenario the conditions to have ${ }_{1}={ }_{2}=0$ as a unique equilibrium? The borrowing constraint already changes the nature of the equilibrium since in period 2, the loan must be paid back out of tax revenues from law-abiding citizens:

$$
B(1+1 /)<i_{2} A K
$$

Constraint (6) sets a lower bound on i2. Moreover, in the second period, in order to have $\mathbb{R}_{2}=0$, one must have:

$$
\begin{aligned}
& q_{2}\left(i S \text { i } { } ^ { \circ } \text { i } B \left(1+{ }^{1 / A}+i_{2} A K\left(1 ; \mathbb{R}_{2}\right)\left(1 ; \mathbb{B}_{1}\right)+\right.\right. \\
& \left(1 ; \exists\left(B+i_{1} A K\left(1 ; \mathbb{B}_{1}\right)\right)\right), \quad i_{2} 8 \mathbb{B}_{2}
\end{aligned}
$$

Finally, in order to prefer choosing being a producer rather than a predator in period 1 , given that $\mathbb{R}_{2}=0$, we must have

$$
\begin{aligned}
& \left(1 ; \mathbb{B}_{1}\right)\left[A K\left(1 ; i_{1}\right)+A K\left(1 ; i_{2}\right)\right] \\
& >\left(1 ; \mathbb{B}_{1}\right)\left[A K\left(1 ; q_{1}\left(; S ; \quad \mathbb{R}_{1}^{0}+G_{1}\right)\right)+\right. \\
& \left.A K\left(1 ; q_{2}\left(; S ; \mathbb{B}_{1}^{0}+G_{2}\right)\right)\right] 8 \mathbb{B}_{1} \\
& \text { with } G_{1}=B+i_{1} A K\left(1 ; B_{1}\right) \text { and } \\
& \mathrm{G}_{2}=i_{2} A K\left(1 ; \mathbb{B}_{1}\right)+ \\
& \left(1 ; \quad \exists\left(B+i_{1} A K\left(1 ; \mathbb{B}_{1}\right)\right) ; B\left(1+{ }^{1 / A}\right.\right.
\end{aligned}
$$

Conditions for the existence of a unique equilibrium law enforcement path are expressed in the following proposition:

Proposition $4 \mathrm{~A}$ unique law enforcement with external borrowing involves $i_{1}, i_{2}>0$ which are both increasing in $B$. This equilibrium may not exist if \pm is high or $\mathrm{A}$ and $\mathrm{K}$ are too low.

Proof of proposition 4: In order to satisfy both the reimbursement constraint and have $\mathbb{B}_{2}=0$, we must have $q_{2}\left(i_{S} i^{\circ}{ }_{i} B(1 / 2+\#+(1 ;\right.$ $\left.\#_{i_{1} A K}\left(1 ; B_{1}\right)\right)=i_{2}$ while satisfying $B\left(1+1_{1 / A}=i_{2} A K\right.$. The latter sets 
a minimum threshold $\frac{B\left(1+{ }^{+1}\right.}{A K}$ on $i_{2}$ which is an increasing function of $B$. In order to have $\mathbb{B}_{2}=0$, we must thus have

$$
B\left(1+1 / A=q_{2}\left(i S _ { i } { } ^ { \circ } i B \left(1 / 2+ \pm+\left(1 ; \#_{i 1} A K\left(1 ;{ }_{1}\right)\right) A K\right.\right.\right.
$$

There is a unique solution $B{ }^{x}\left(i_{1}\right)$ to equation 9 , when it exists, (with $\left.\frac{d^{B}}{d_{i 1}}>0\right)$ because $B\left(1+{ }^{1 / A}\right.$ is upward sloping in $B$ and $q_{2}\left(i S_{i}{ }^{\circ} i B(1 / 2+\right.$ $\sharp^{2}+\left(1 ; \#_{i_{1} A K}\left(1 ; \mathbb{B}_{1}\right)\right) A K$ is downward sloping in $B$. Inversely, the solution to 9 in terms of $i_{1}$ is:

$$
i 1=\frac{q_{2}^{i} \frac{B(1+1 / A}{A K}+B\left(1 / 2+ \pm+S+{ }^{\circ}\right.}{\left(1 ; \pm A K\left(1 ;{ }_{1}\right)\right.}
$$

with $\frac{d i_{1}}{d B^{x}}>0$. On the other hand, B must be suф ciently large so as to induce agents to become producer in period 1 . Indeed, taking (8) , following the reasoning of the proof of proposition 3 , the choice of being a producer rather than a predator in period 1 implies that the following condition must be satis..ed:

$$
\left[q_{2}\left(; S ; \mathbb{B}_{1}^{\circ}+G_{2}\right)+q_{1}\left(; S ; \mathbb{B}_{1}^{\circ}+B+i_{1} A K\left(1 ; \mathbb{B}_{1}\right)\right]>i_{1}+i_{2}\right.
$$

for all $\AA_{1}<1$ and $i_{2}, \frac{B(1+1 / A}{A K}$ and $i_{1}, i_{1}(B)$. This is satis. ed when $B$ satis..es the following constraint:

$$
\left[q_{2}\left(i_{S_{i}}{ }^{\circ}+G_{2}\right)+q_{1}\left(i S_{i}{ }^{\circ}+B\right)\right]>i_{1}(B)+\frac{B\left(1+{ }^{1 / A}\right.}{A K}
$$

with $G_{2}=i_{2} A K\left(1 ;{ }_{1}\right)+\left(1 ; \quad \exists\left(B+i_{1} A K\left(1 ;{ }_{1}\right)\right) ; B\left(1+{ }_{1} / A\right.\right.$ evaluated at $\Theta_{1}=1$ which gives $G_{2}<0$ and $q_{2}=0$. The constraint becomes then:

$$
\mathrm{q}_{1}\left(\mathrm{iS}_{\mathrm{i}^{\circ}}+\mathrm{B}\right)>i_{1}(\mathrm{~B})+\frac{\mathrm{B}\left(1+{ }^{1 / A}\right.}{\mathrm{AK}}
$$

It is easy to see that the RHS is an increasing convex function of $B$ and the LHS is an increasing concave function of $B$. Therefore this sets, at best, an interval $\left[B_{\min } ; B_{\max }\right]$ in which $B$ needs to belong in order to eliminate the coordination problem of law enforcement. This interval may not even exist when the function of the RHS $i_{1}(B)+\frac{B\left(1+{ }^{+1 / R}\right.}{A K}$ is always above the functionof the LHS $q_{1}\left(\mathrm{iS}_{i^{\circ}}{ }^{\circ}+\mathrm{B}\right)$ : Once $\mathrm{B}$ is chosen, this in turn determines $i_{1}$ and i2. Note ..nally that whenever it exists $B$ min has to be strictly larger than $\mathrm{S}+{ }^{\circ}: ¥$ 
The intuition for the result is the following. B must be high enough so as to convince agents in period 1 to become producers rather than predators. The higher $\mathrm{B}$, the higher the amount that must be reimbursed in period 2 . This has two exects: ..rst it increases $i_{2}$ because of the reimbursement constraint but second, it increases $i_{1}$ required to invest in repression technology in period 1 so as to maintain incentives not to become predators in period 2 . Since $B$ increases both $i_{1}$ and $i_{2}$, the necessary amount of foreign borrowing necessary to deter predators in period 1 may make it impossible to raise enough taxes that period to deter predators in period 2 also. This will be the case if AK is small enough or if \pm is close enough to 1 , conditions which are likely to hold in transition economies, as well as in many other economies. A nother way of putting it is that even if external borrowing can solve the coordination problem in the ..rst period to eliminate the bad equilibrium, it then may not be in a position to do so in the second period because of the conłicting objectives of reimbursing the foreign debt and of investing enough in repressive technology.

\section{Borrowing and accession.}

We now take the same model as above and assume that the transition country borrowing in the ..rst period has the possibility of accession to the European Union in the second period. This case mirrors closely that of Central European countries like Poland, the Czech republic, Hungary, Slovenia and Estonia who are the "..rst round" accession countries.

It is assumed that, after accession, the repression technology is jointly ..nanced by the Union. Even though this does not refect the current institutional reality of public ..nances in the European Union, it is not unlikely that such repression technology will, at least partly, be ..nanced in common. M oreover, public ..nances are fungible and accession to the E uropean Union is likely to give those countries access to structural funds from the European Union which can contribute to a substantial part of those countries' budget. We also want to analyze the exects of conditionality of accession. It is assumed that under conditionality, accession can only take place afer the observation of $\AA_{1}=0$ in period 1 .

Denote by $\mathrm{K}^{-}$the capital per capita in the Union after accession. Call $\mu=\underline{1}$ the share of the initial country and call $R_{0}$ the initial repression budget 
in the European Union. In order to keep things simple, we also assume that all relevant variables are expressed in per capita terms. We assume no redistribution so that the per capita income of accession country members remains $A K$.

The second period constraint to induce $\AA_{2}=0$, which will also be the constraint for the Union will be

$$
\begin{aligned}
& o_{2}\left(\mathrm{i} \mathrm{i}^{\circ}+\mathrm{G}_{2}\right), \quad i_{2} \\
& G_{2}=i_{2} A K^{-}\left(1 ; \Re_{2}\right)\left(1 ; \Re_{1}\right)+
\end{aligned}
$$

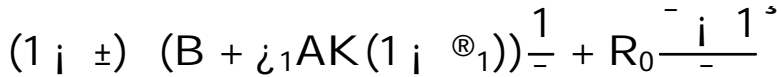

A s we can see, reimbursement of the debt is cancelled out since repression technology is ..nanced out of a common budget. Also, if $R_{0}$ and ${ }^{-}$are high enough, the equilibrium with $\AA_{2}=0$ can easily be sustained.

On the other hand, with conditionality, when looking at period 1 choices, we must look at the consequences of not meeting conditionality. We use the superscripts a for accession $\left(\mathbb{R}_{1}=0\right)$ and na to indicate no accession $\left(\Re_{1}>0\right)$.

Conditional on $\AA_{1}=0$; a producer who chooses to be a producer in period 2 gets AK $\left(1 ; i_{1}\right)+\left(1 ; \mathbb{R}_{2}^{a}\right) A K\left(1 ; i i_{2}^{a}\right)$ whereas if he chooses to be a predator in period 2 , he gets $A K\left(1 ; i_{1}\right)+\left(1 ; \quad{ }_{2}^{a}\right) A K\left(1 ; q_{2}^{a}\right)$. When condition 10 is met, the payo of the former is higher than of the latter. However, if $\mathbb{R}_{1}>0$, conditionality implies that accession will not take place. In that case, a producer in period 1 gets $\left(1 ; \mathbb{R}_{1}\right)\left[A K\left(1 ; i_{1}\right)+\left(1 ; \mathbb{R}_{2}^{\text {na }}\right) A K\left(1 ; \quad i_{2}^{\text {na }}\right)\right]$ if he chooses to be a producer in period 2 and gets $\left(1 ;{ }_{1}\right)\left[A K\left(1 ; i_{1}\right)+\right.$ $\left(1 ;{ }_{2}^{\text {na }}\right) A K\left(1 ; q_{2}^{\text {na }}\right)$ ] if he chooses to be a predator in period 2 . In order to compute the equilibrium, we need to know what happens outside equilibrium, i.e. outside accession. Since there are multiple equilibria in period 2, we will assume a probability $\cong$ of the bad equilibrium with $\mathbb{R}_{2}^{\text {na }}=1$ and a probability $(1 ; \underline{0})$ of the good equilibrium with $\mathbb{R}_{2}^{\text {na }}=0$. A nother possibility would be to assume that privatization is undone but that does not seem to be a very realistic assumption.

We then get the following proposition:

Proposition $5 \mathrm{~W}$ ith accession, the law enforcement equilibrium is sustainable as unique equilibrium with a positive but lower amount of borrowing $B(\underline{0})$ ( with $\frac{d B}{d o}<0$ ) than without accession whereas without conditionality, it is sustainable with $B=0$ and $i_{1}=0$. 
Proof of proposition 5: Let us look at individual choices in period 1 given $\AA_{2}=0$.

Conditional on $\mathbb{R}_{2}=0$ if $\mathbb{B}_{1}=0$, and the multiplicity of equilibria if $\mathbb{B}_{1}>0$, somebody who chooses to be a producer in period 1 gets

$$
A K\left(1 ; \quad i_{1}\right)+A K\left(1 ; \quad i_{2}^{a}\right)
$$

if $\AA_{1}=0$ and

$$
\left(1 ; \mathbb{B}_{1}\right)\left[A K\left(1 ; \quad i_{1}\right)+(1 ; \quad 0) A K\left(1 ; \quad i_{2}^{\text {na }}\right)\right]
$$

if $\AA_{1}>0$.

A $n$ individual who decides to become a predator in period 1 gets

$$
\left(1 ; \bigotimes_{1}\right)\left[A K\left(1 ; q_{1}\right)+(1 ; \stackrel{o}{1}) A K\left(1 ; q_{2}^{\text {na }}\right)\right]
$$

with

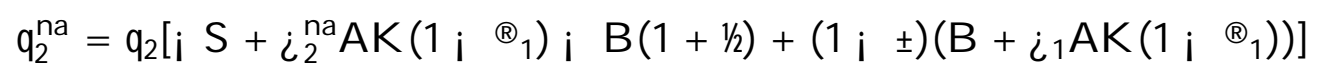

and

$$
i_{2}^{\text {na } A K}, B(1+1 / \mathrm{A}
$$

Recall that in the case where there is no accession, the country has to satisfy its debt repaiements whenever it can (ie. in the good equilibrium )

The choice of being a producer rather than a predator in period 1 implies that the following condition must be satis..ed:

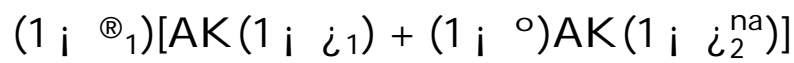

$$
\begin{aligned}
& >\left(1 ; \mathbb{R}_{1}\right)\left[A K\left(1 ; q_{1}\right)+(1 ; \stackrel{\circ}{\circ}) A K\left(1 ; q_{2}^{\text {na }}\right)\right]
\end{aligned}
$$

for all $\AA_{1}<1$. This is satis..ed when:

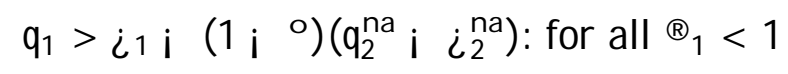

with

$$
q_{1}=q_{1}\left(i S ; \mathbb{R}_{1}^{0}+B+i_{1} A K\left(1 ; \mathbb{R}_{1}\right)\right]
$$


Evaluating these expressions at $\AA_{1}=1$; one gets $q_{2}^{\text {na }}=0$, and the condition

$$
q_{1}\left(i S i^{\circ}+B\right]>i_{1}+\left(1 ; \stackrel{o}{)} i_{2}^{\text {na }}\right.
$$

The condition for a good equilibrium in period 2 with no accession is similarly written as

$$
q_{2}\left[i S+i_{2}^{\text {na } A K}\left(1 ; \mathbb{B}_{1}\right) i \quad B\left(1+1 / A+\left(1 ; \quad \#\left(B+i_{1} A K\left(1 ; \mathbb{B}_{1}\right)\right)\right], \quad i_{2}^{\text {na }}\right.\right.
$$

and adding the borrowing reimbursement constraint:

$$
i_{2}^{\text {na } A K}, B(1+1 / A
$$

Now clearly, B $>0$ in order to satisfy ??.

T wo strategies are possible to keep $B$ as low as possible. One involves setting $i_{1}=0$ and thus $q_{1}\left(i_{S_{i}}{ }^{\circ}+B\right]>\left(1 i^{\circ}\right) i_{2}^{\text {na }}$ with the right hand side, and thus the required $B$; decreasing with 0 .

Calling $i_{2}^{\text {ana }}$ the level of $i_{2}^{\text {na }}$ satisfying $q_{2}\left[i S+i_{2}^{\text {ana }} A K\left(1 ; \mathbb{B}_{1}\right) ; B(1 / 2+\right.$ $\pm)]=i_{2}^{\text {ana }}$ when it exists, we will thus have

$$
i_{2}^{\text {na }}=\operatorname{maxf} \frac{B(1+1 / A)}{A K} ; i_{2}^{\text {xna }} g
$$

If $i_{2}^{\text {na }}=\frac{B\left(1+{ }^{1 / A}\right)}{A K}$, the constraint $q_{1}\left(i_{S} i^{\circ}+B\right]>(1 ; \stackrel{\circ}{\circ}) \sum_{2}^{\text {na }}$ is easier to satisfy for any $v$ than the equivalent constraint in the case of foreign borrowing: $q_{1}\left(i_{S_{i}}{ }^{\circ}+B\right)>i_{1}(B)+\frac{B\left(1+1^{1 / A}\right.}{A K}$. It is less obvious if $i_{2}^{\text {ana }}$ is very big.

A nother strategy involves setting $i_{2}^{\text {na }}=\frac{\mathrm{B}\left(1+{ }^{+1 / A}\right.}{\mathrm{AK}}$ and setting $i_{1}$ in a way as to satisfy 12 , using the same logic as in the model with foreign borrowing.

Using 13 and 12 as an equality and substituting in ??, one gets that B should ..nally satisfy:

$$
q_{1}\left(i^{S} i^{\circ}+B\right)>\varepsilon_{1}(B)+(1 ; \stackrel{o}{B}) \frac{B\left(1+{ }^{1 / A}\right.}{A K}
$$

with

$$
E_{1}(B)=\frac{q_{2}^{i}{ }^{3} \frac{B(1+1 / A}{A K} i\left(1 ; \pm B+S+B\left(1+1 / A \Theta_{1}\right.\right.}{\left(1 ; \pm A K\left(1 ; \mathbb{B}_{1}\right)\right.}
$$


When $\cong$ increases, the required $B$ to satisfy 14 also decreases. Note the dixerence between 14 and what we had with foreign borrowing

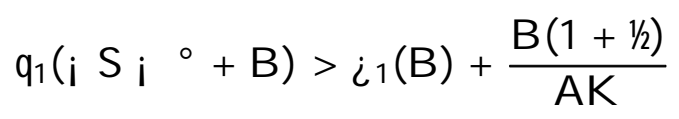

with

$$
i_{1}=\frac{q_{2}^{i_{1}^{3}} \frac{B\left(1+1^{1 / A}\right.}{A K}+B(1 / 2+ \pm)+S+0}{\left(1 ; \pm A K\left(1 ;{ }_{1}\right)\right.}
$$

One sees easily that $\ell_{1}(B)<i_{1}(B)$ and since $0<1$ the right hand side of 14 is smaller than in the case of foreign borrowing, and thus the required $B$ to satisfy the ..rst period constraint is also smaller. Choosing the strategy minimizing $B$ thus always leads to an amount of borrowing that is smaller than in the case of foreign borrowing. In both cases, when 0 decreases, the required $B$ also decreases.

Let us now look at what happens without conditionality. In this case, the choice in period 1 of being a producer rather than a predator implies that the following condition must be met:

$$
\begin{aligned}
& \left(1 ; \mathbb{B}_{1}\right)\left[A K\left(1 ; \quad i_{1}\right)+A K\left(1 ; \quad i_{2}^{a}\right)\right] \\
& >\left(1 ; \mathbb{B}_{1}\right)\left[A K\left(1 ; q_{1}\right)+A K\left(1 ; q_{2}^{a}\right)\right]
\end{aligned}
$$

Thus, to have $\mathbb{R}_{1}=0$, one must have $q_{1}>i_{1} i \quad\left(q_{2}^{a} i \quad i_{2}^{a}\right)$. Since in equilibrium, $q_{2}^{a}>i_{2}^{a}$; the enforcement equilibrium can be achieved with $B=$ 0 and thus $q_{1}=0$ with $i_{1}=0 . \neq$

The result that borrowing is smaller with accession was expected but the reasons for the equilibrium amount of borrowing are somewhat surprising, and in particular the result that without conditionality, no borrowing is required in equilibrium to sustain law enforcement in the ..rst period. So let us dwell on the intuition for prop 5.

Borrowing is needed not only in order to deter from predation in period 1, but also to deter from becoming a predator in both periods given the irreversibility of that choice. Under conditionality, this is done against the out of equilibrium path where agents deviate and where accession does not happen. In other words, giving an incentive to an agent not to become a predator, and thus eliminating the bad equilibrium, must be seen in a context where other agents would be deviating, and thus accession not be reached. 
The amount of borrowing is smaller than in the case of foreign borrowing because we must allow for the possibility of multiple equilibria in period 2. In fact, the lower the probability of the good equilibrium the lower the equilibrium amount of borrowing necessary, the smallest amount being $B=$ $\mathrm{S}+{ }^{\circ}$, the quantity needed to sustain the static enforcement equilibrium. ${ }^{5}$ It is interesting that with conditionality the prospect of accession does not infuence the ..rst period choice of agents but that it is the non accession ox equilibrium path that inłuences their choice.

Conditionality is thus not et cient here since the accessing economy must, in order to have access to a superior repression technology in period 2, prove that it is able in period 1 to achieve the law enforcement equilibrium.

By contrast without conditionality, zero borrowing is necessary to achieve the law enforcement equilibrium in the ..rst period. With unconditional accession, one can axord to have $i_{1}=0$ and thus not borrow at all to sustain the good equilibrium since in equilibrium $q_{2}>i_{2}$, with or without conditionality. Therefore, as long as $i_{1}=0, q_{1}=0$ is sul cient as an incentive for all agents to become producers. In other words, the better prospects for producers than for predators after accession are suc cient to deter would-be predators. The absence of conditionality maintains this incentive, even if some agents considered deviating.

W ith conditionality, accession is conditional on what others do. Without conditionality, this is no more the case. The prospect of accession itself is what gives incentives. In a way, conditionality reduces the expected bene..t from accession because of the coordination problem individuals are facing in the light of accession. Conditionality creates a coordination problem that is absent without conditionality. We think that this insight is interesting because it shows that conditionality can be counterproductive when coordination is necessary to achieve the conditions for accession.

\footnotetext{
If one could commit to eliminate the good equilibrium in period 2 through a strategic move in the ..rst period, then it would be possible to set $\mathrm{B}=\mathrm{S}+{ }^{\circ}$. However, it is not obvious how such a commitment may be enforced given that i2 can be chosen in a way as to make the second period good equilibrium feasible (and pareto-superior to the bad equilibrium).
} 


\section{Conclusion}

In conclusion, we want to emphasize both the policy implications and the theoretical insights derived in this paper.

In terms of policy implications, we have shown two dixerent institutional responses to the coordination problem in law enforcement. The ..rst one is dualism, illustrated by the Chinese transition experience with the coexistence of on one hand the maintain of direct state control over economic resources, and on the other hand, a very liberalized non state sector. This allows for both credible law enforcement while giving incentives for productive activity. The second mechanism is accession to the European Union where we have shown that the prospect of accession can in itself be suc cient to lead private agents to coordinate on the law enforcement equilibrium before transition.We think the accession exects may explain part of the dixerence between the dixerent trajectories in R ussia and in Central E uropean countries like Poland. More generally, the accession exects on the success of reforms in Central European countries has been neglected in the transition literature where reform trajectories are analyzed independently of their international context. As argued by Roland (1997) and Csaba (1997), the geopolitical aspects of transition with Central Europe breaking away from Russian domination to join the Western European club, has strongly axected the perception of the costs and bene..ts of reform in Central Europe compared to Russia. An implication of this idea is that the comparison between Polish and Russian transition cannot be done solely in terms of the strategies chosen. A nother implication is that R ussia which lacks anything like the prospect of accession should be compared to other countries that must ..nd alone their path to success in transition. This points to the relevance of the Chinese transition experience for Russia and to the relevance of dualism in transition.

In terms of theoretical insights of the model that go beyond transition, we want to emphasize both the dynamics of coordination under the enforcement externality and the result that conditionality of accession can be counterproductive. The interesting aspect about the dynamics of coordination is related to the fact that the last period repression expenditures necessary to obtain a unique equilibrium create a positive intertemporal incentive to become a producer rather than a predator. It is this incentive that allows to reduce the amount of state control over resources in the dynamic as compared to the static model. It is also this incentive that allows to eliminate the need for 
borrowing in the accession case without conditionality. M ore interesting from the positive point of view is the result that conditionality can be counterproductive because it creates a coordination problem of its own. This result is quite new. Standard thinking on conditionality is based on traditional principal-agent and moral hazard models where the country reveiving the loan is viewed as a single agent. Whereas in many cases this approximation may be valid, in other cases, it may be missing the inmportant dimension of coordination. 


\section{REFERENCES}

2 Berkowitz, D. and W.Li "Decentralization in Transition E conomies: A Tragedy of the Commons?"

Byrd, W illiam A., "T he Impact of the T wo-T ier Plan/ M arket System in Chinese Industry," J ournal of Comparative Economics, 11, 295-308, 1987.

Byrd, William A., "Plan and Market in the Chinese E conomy: A Simple General Equilibrium Model," J ournal of Comparative Economics, 13, 177-204, 1989.

\section{Csaba, L.}

Furlong W. " Crime Commission and Prevention", J ournal of Public E conomics, 51; 1993, 391-413.

Gordon, R., Bai Chong-En and D. Li, "Eф ciency Losses from Tax Distortions vs. Government Control ", European Economic Review, 1999, forthcoming.

Grossman, Herschel

J ohnson, S. Kaufmann, D. and A. Shleifer, "The Unoł cial E conomy in Transition", Brookings Papers on Economic Activity, 2: 159-239.

Lau, Lawrence J ., Y ingyi Qian, and Gerard R oland, "Pareto-Improving E conomic R eforms through Dual-Track Liberalization," E conomics Letters, 55 (2), 285-292, 1997.

Lau, Lawrence J ., Y ingyi Qian, and Gerard Roland "R eform without L osers: An Interpretation of China's Dual-Track Approach to Transition ", mimeo Stanford University , 1997.

M oene A. 1990: "How Corruption may Corrupt", J ournal of Economic Behavior and Organization", (13),1, 63-76.

Moselle B. and B. Polak: "A narchy, Organized Crime and Extortion: A Cynical Theory of the State", Mimeo 1994 Harvard.

North, D. C, Institutions, Institutional Change and E conomic Performance . Cambridge, Cambridge University Press, 1990.

R oland, G. "Political Constraints and the Transition Experience", in S. Zecchini (ed.), Lessons from the Economic Transition, Kluwer (1997), pp. 169-188. 
Roland, G érard and T hierry Verdier, "Transition and the Output Fall", E conomics of Transition, 1999, forthcoming.

Savvateev, A. "Production and Rent-Seeking Behavior", Working Paper New Economic School Moscow, 1998.

Sicular, T., "Plan and Market in China's Agricultural Commerce," J ournal of Political Economy, 96(2): 283-307, A pril, 1988. 